\title{
Otomyiasis: Systematic Review
}

\author{
María Teresa Rodríguez-Ruiz ${ }^{1}$ \\ María Alejandra Chirveches ${ }^{3}$ \\ Ana María Acosta 2 \\ 1 Department of Emergency, Hospital Universitario San Ignacio, \\ Facultad de Medicina de la Pontificia Universidad Javeriana, \\ Bogotá, Colombia \\ 2 Departament Otolaryngology, Facultad de Medicina de la Pontificia \\ Universidad Javeriana, Bogotá, Colombia \\ ${ }^{3}$ Department of Clinical Epidemiology and Biostatistics, Facultad de \\ Medicina de la Pontificia Universidad Javeriana, Bogotá, Colombia
}

Eduardo Cifuentes-Cardozo ${ }^{1}$

\begin{abstract}
Address for correspondence Diego Rosselli, MD, PhD, Department of Clinical Epidemiology and Biostatistics, Facultad de Medicina de la Pontificia Universidad Javeriana, Carrera 7 No. 40-62, Bogotá, 110311, Colombia (e-mail: diego.rosselli@gmail.com).
\end{abstract}

\begin{abstract}
Keywords

- diptera

- ear diseases

- larva

- myiasis

- parasites

- sarcophagidae

Introduction Myiasis is a disease caused by fly larvae that grow in the tissues of animals and humans. It can cause a variety of local symptoms, like erythema or pain, depending on its location, and generalized symptomatology, such as fever and malaise. Myiasis can generate severe complications, for instance sepsis, or directly impact vital tissues. Its management varies depending on the location, and on the preferences of the doctor that faces this challenge. Myiasis usually occurs in tropical countries, and, in many places, it is not a rare condition. The cases are rarely reported, and there are no published management protocols. Objective To review the literature regarding the most common agents, the predisposing factors and the treatment alternatives for otic myiasis, a rare form of human myiasis caused by the infestation of fly larvae in the ear cavities.

Data synthesis We present a systematic review of the literature. The search in five databases (Medline, Embase, Cochrane Database of Systematic Reviews, LILACS and RedALyC) led to 63 published cases from 24 countries, in the 5 continents. The ages of the patients ranged from newborn to 65 years old. The most common agents belong to the Sarcophagidae or Calliphoridae families. Chronic otitis media, previous otic surgical procedures, mental deficit, alcohol or drug abuse, sleeping outdoors, prostration, and malnutrition were predisposing factors. The treatment alternatives are herein discussed.

Conclusion The results highlight the need for monitoring, follow-up and standardization of medical approaches.
\end{abstract}

\section{Introduction}

The word myiasis was first used by Hope, in $1840,{ }^{1}$ to refer to a parasitic disease caused by certain fly larvae during a particular stage of their development when they feed on animal and human tissues. The geographic distribution of the condition is almost exclusively limited to hot, tropical areas, and its etiological agent varies from one region to another. Depending on the affected organ, myiasis can be classified in cutaneous, enteric, ophthalmic, nasopharyngeal, urogenital, oral and, as in our case, the less common otic myiasis. This article presents a specific systematic review of the published literature on otic myiasis.

\section{Review of the Literature}

\section{Methodology}

A systematic review of the literature was made in June of 2016 on five different databases (Medline, Embase, Cochrane Database of Systematic Reviews, LILACS and RedALyC). To widen the sensitivity of the search, we used free terms; -Supplementary Material 1 (available online only) lists the received

July 27,2017

accepted

November 15, 2017

published online

March 13, 2018
DOI https://doi.org/

$10.1055 / \mathrm{s}-0037-1617427$. ISSN 1809-9777.
Copyright (e 2019 by Thieme Revinter

Publicações Ltda, Rio de Janeiro, Brazil
License terms

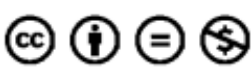


search terms as well as the search constructs for the different databases. We conducted a systematic review by following the guidelines of the Preferred Reporting Items for Systematic reviews and Meta-Analyses (PRISMA) ${ }^{2}$ (-Supplementary Material 2). No limits were applied for age, year of publication, or language. Articles without an abstract were excluded. The titles and summary lists were evaluated by two researchers simultaneously to evaluate exclusion criteria: those that were clearly irrelevant, as well as those focused on therapeutic treatment for larvae, non-human animal studies, forensics, entomologic studies, or patients with risk factors such as recent surgical wounds, cancer or ulcers. Information from the full-text remaining articles was collected in a predesigned Excel spreadsheet - Supplementary Material 3. The quality of the publications was assessed using the Joanna Briggs Institute scale for case series, ${ }^{2}$ and the Center for Evidence-Based Management (CEBMa) scale for individual case report studies. ${ }^{3}$

\section{Results}

From the 272 initial studies (-Fig. 1), ${ }^{4} 82$ of them were selected for full text review, 29 of which could not be found (23 of these were published between 1918 and 1994). After a second exclusion analysis, 6 articles were rejected for being considered irrelevant, and 7 more for failing to meet the quality criteria. The remaining 40 studies reported 63 cases from 24 countries (Argentina, Australia, Belize, Canada, Colombia, Costa Rica, Cuba, Dominican Republic, Germany, India, Iran, Italy, Malaysia, Morocco, Nigeria, Paraguay, Poland, Rumania, Saudi Arabia, South Korea, Spain, Thailand, Turkey, and United States). - Table $\mathbf{1}^{5-44}$ summarizes the information from these articles (-Supplementary Material 4).

Of the 63 cases reported, 34 were men (62\%) and 21 were women (in 8 cases, no gender was reported). The ages ranged from 2 days to 65 years old, with an average of 26 . Chronic otitis media, previous otic surgical procedures, mental deficit, alcohol and drugs use, sleeping outdoors, prostration, malnutrition, jaundice and previous episodes of otomyiasis were predisposing factors. In 30 patients, no risk factors were mentioned. As for the etiological agents, the parasite was identified in 44 cases, 23 corresponded to the Sarcophagidae family, 20 to the Calliphoridae family, and 1 to the Oestridae. Eleven cases were reported in Latin America ( 2 in Argentina, 2 in Colombia, 2 in the Dominican Republic, 2 in Paraguay and one each from Belize, Costa Rica, and Cuba); 7 of them informed the agent, which was always from the Calliphoridae family.

Complications were reported in 23 of the 63 cases, describing tympanic perforation, chronic otitis media, temporal bone extension, cartilaginous destruction, cellulitis and perichondritis. The use of extraction with clamp, either
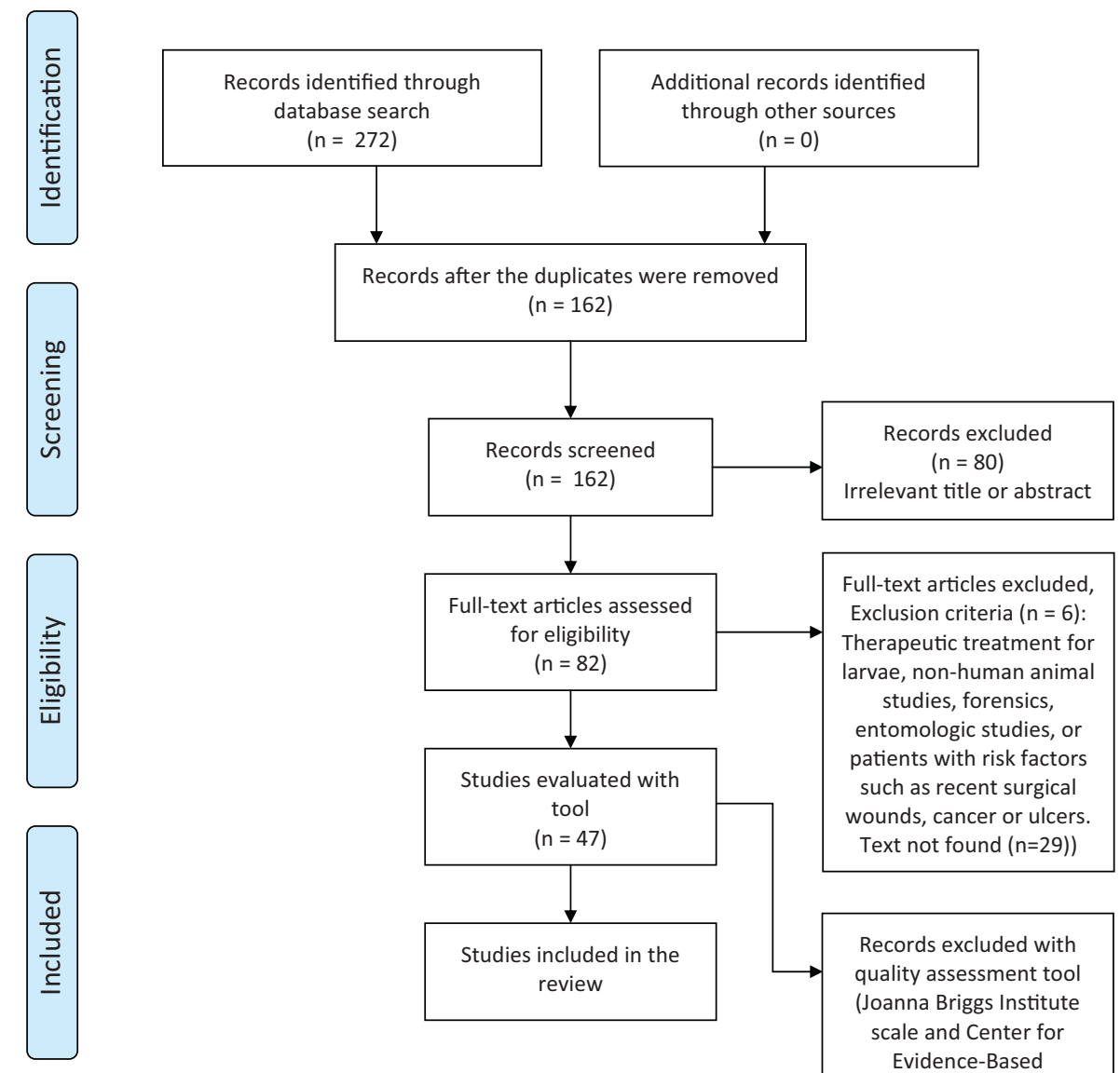

Full-text articles excluded, Exclusion criteria $(n=6)$ : Therapeutic treatment for larvae, non-human animal studies, forensics, entomologic studies, or patients with risk factors such as recent surgical wounds, cancer or ulcers. Text not found $(n=29)$ )

Records excluded with quality assessment tool (Joanna Briggs Institute scale and Center for Evidence-Based management [CEBMa] scale) $(n=7)$

Fig. 1 Prisma diagram of the search strategy. ${ }^{4}$ 


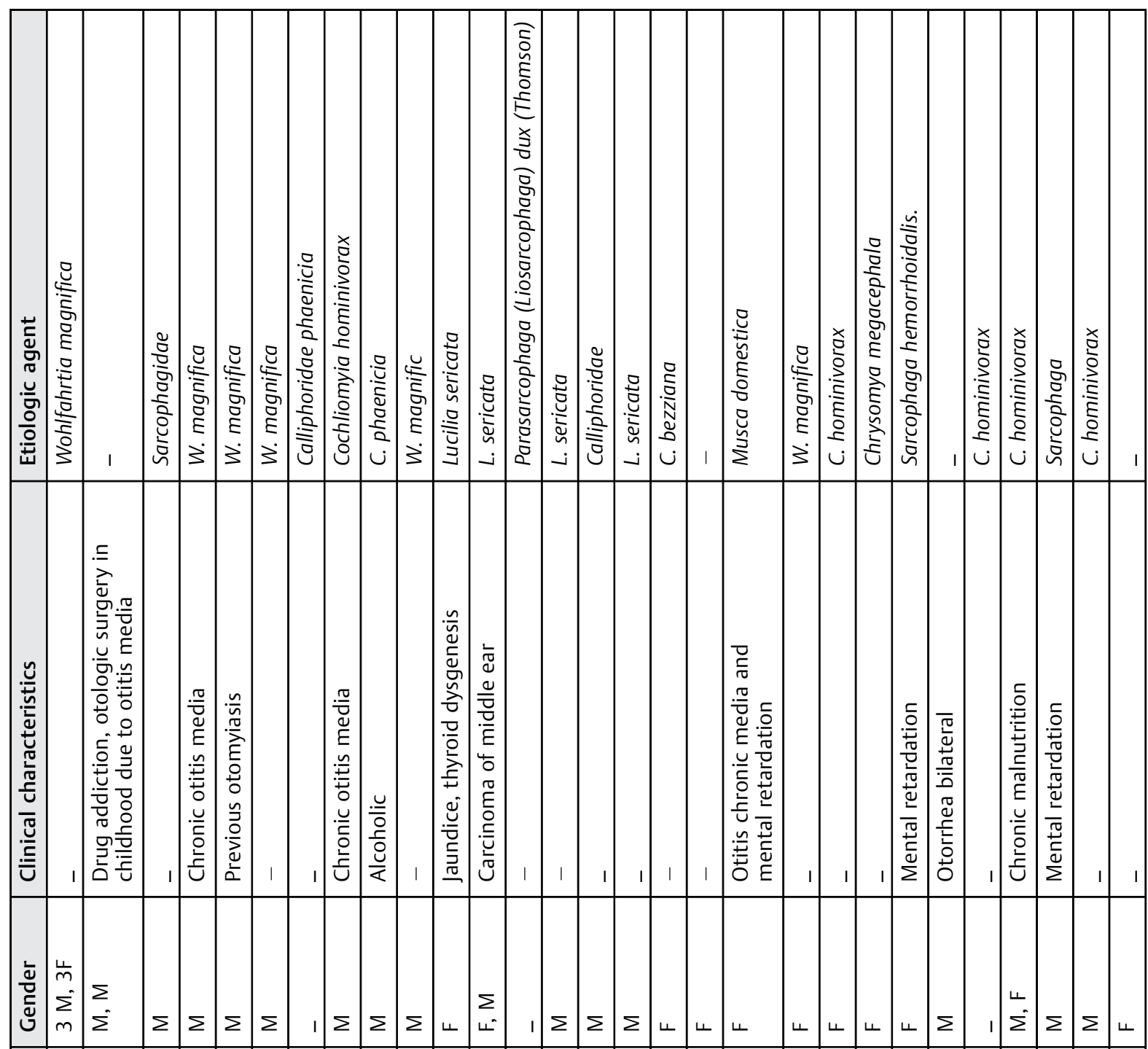

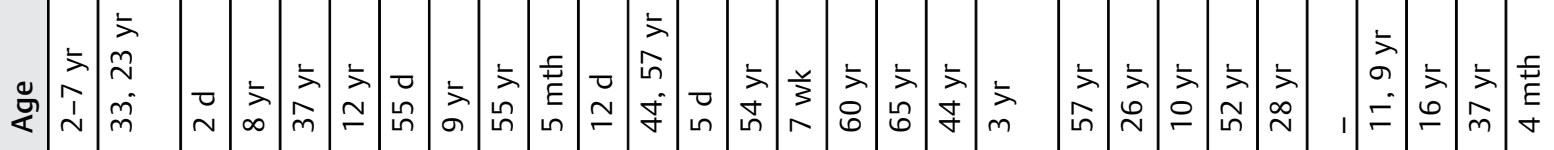




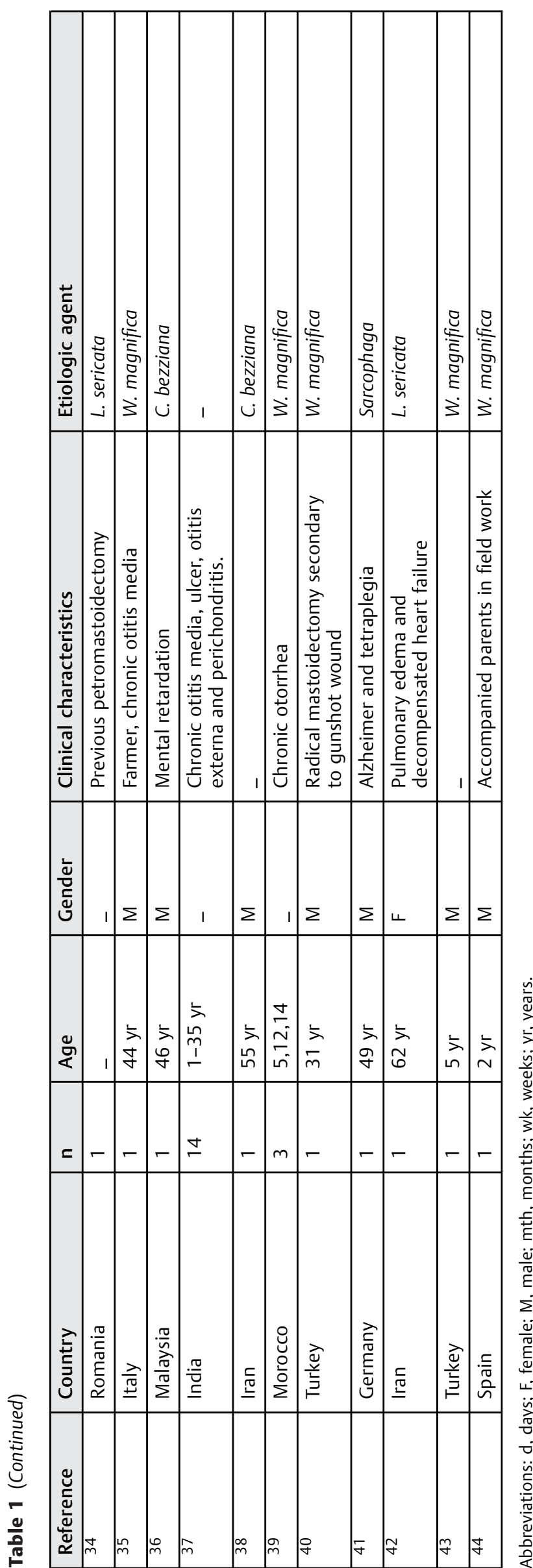

with or without anesthesia, was reported, and, in some cases, with the aid of suction and complementary otic lavage with different types of substances, such as saline, lidocaine, alcohol, and hydrogen peroxide. In 39 cases, antibiotics were mentioned, topical, oral or parenteral.

\section{Discussion}

Myiasis is a relatively common public health problem in developing countries, mainly in hot, tropical areas. ${ }^{45}$ There are, however, no clinical practice guidelines for diagnosis or treatment of this disease. Otomyiasis occurs when the female fly, perhaps attracted by bad odor, deposits its larvae in the auditory meatus. ${ }^{46}$ Chronic otitis media or others otic pathologies are, therefore, predisposing factors. A recent review article, with 45 cases of otomyiasis, ${ }^{47}$ considers that sanitary conditions play an important role, but other triggers are: low socioeconomic status, swimming in stagnant waters, diabetes mellitus, alcoholism, prostration and suppurative chronic otitis media. Our review shows chronic otitis media as a main risk factor that favor larvae growth.

Taxonomic division establishes several families derived from the order Diptera: Oestridae, Calliphoridae and Sarcophagidae are the most important. The species Wohlfahrtia magnifica, which belongs to the latter family, is a must-type larva, meaning that it requires living in a host tissue to complete its development. This species is the predominant etiologic agent worldwide, ${ }^{47}$ but Sarcophagidae is the predominant family in Europe, and in the Middle East. In Latin America, all the cases that reported the larvae belonged to the Calliphoridae family.

After having diagnosed myiasis through physical examination and, in some cases, through diagnostic images, the treatment must begin as soon as possible, including direct or surgical extraction of the larva. ${ }^{48}$ To achieve that goal, the literature shows different treatments, which include antiparasitic therapy with oral ivermectin ${ }^{49,50}$ or topic permethrin. ${ }^{5}$ The occlusion of the lesion is used to force the larvae to exit, thus facilitating its manual extraction; this can be done using olive oil or petroleum jelly. Another popular treatment, commonly used in rural areas, ${ }^{45}$ involves placing a piece of bacon to attract the larvae, as reported in the Villamizar case. ${ }^{6}$

The treatment should also include extraction using alligator forceps under micro-otoscopy vision, in some cases anesthesia, suction and ear washes with saline solution $0.9 \%$. Systemic antibiotic therapy is also used when there is chronic otitis media, as discussed by Yuca et $\mathrm{al}^{5} \mathrm{The}$ location of the infection and its proximity to the brain are a concern, and authors have discussed the risk of myiasic meningitis and eventually death of the patient, but we did not find this complication reported in the literature.

\section{Final Comments}

Otomyiasis is a parasitic condition that tends to affect vulnerable subjects in tropical countries. Improving personal 
care would reduce the risk. Training health providers is important for early diagnosis and treatment.

Note

All authors contributed equally to this work.

\section{References}

1 Hope FW. On insects and their larvae occasionally found in the human body. Trans Entomol Soc. 1840;2:256-271

2 The Joanna Briggs Institute. Reviewer's Manual. Australia: The Joanna Briggs Institute; 2014

3 Centre for Evidence-Based Management. Critical appraisal of a survey. [updated 2014 June 5]. Available from: http://www. cebma.org/wp-content/uploads/Critical-Appraisal-Questionsfora-Survey.pdf

4 Moher D, Liberati A, Tetzlaff J, Altman DG; PRISMA Group. Preferred reporting items for systematic reviews and meta-analyses: the PRISMA statement. Ann Intern Med 2009;151(04): 264-269, W64

5 Yuca K, Caksen H, Sakin YF, et al. Aural myiasis in children and literature review. Tohoku J Exp Med 2005;206(02):125-130

6 Villamizar J, Sandoval G. Miasis ótica. Acta Otorrinolaringol Cir Cabeza Cuello. 2000;28(03):203-206

7 Ahmad NW, Ismail A, Jeffery J, et al. Aural myiasis in a neonate in peninsular Malaysia. Parasit Vectors 2009;2(01):63

8 Akduman D, Arslan MO, Gul S. A case of otomyiasis in a child with chronic otitis media. Int J Pediatr Otorhinolaryngology Extra 2011;6(03):116-118

9 Bayindir T, Miman O, Miman MC, Atambay M, Saki CE. Bilateral aural myiasis (Wohlfahrtia magnifica): a case with chronic suppurative otitis media. Turkiye Parazitol Derg 2010;34(01):65-67

$10 \mathrm{Al} \mathrm{Jabr} \mathrm{I.} \mathrm{Aural} \mathrm{myiasis,} \mathrm{a} \mathrm{rare} \mathrm{cause} \mathrm{of} \mathrm{earache.} \mathrm{Case} \mathrm{Rep}$ Otolaryngol 2015;2015:219529

11 Bowe Douglas L, Amaro Trapaga E, Sotolongo Guerra F, Alonso Bermudez P. [Otic myiasis in a newborn caused by Calliphoridae larvae of the genus Phaenicia]. Rev Cubana Med Trop 1977;29 (02):75-79

12 Calderón O, Rivera P, Sánchez C, Solano M. Cochliomyia hominivorax (diptera; calliphoridae) como agente causal de miasis aural en un niño de Costa Rica. Parasitol. 1996;20(34):130-132

13 Calvo LM, Suárez MM, Apolinario RM, Martín AM. [Larvae in the external auditory canal and nasal fossae of an alcoholic patient]. Enferm Infecc Microbiol Clin 2005;23(05):323-324

14 Casanova-Roman M, Sanchez-Legaza E, Sanchez-Porto A, Murga C. Aural myiasis in an infant. Infez Med 2010;18(03):175-176

15 Çetinkaya M, Özkan H, Köksal N, Coşkun SZ, Hacimustafaoğlu M, Girişgin O. Neonatal myiasis: a case report. Turk J Pediatr 2008;50 (06):581-584

16 Kaczmarczyk D, Kopczyński J, Kwiecień J, Michalski M, Kurnatowski P. The human aural myiasis caused by Lucilia sericata. Wiad Parazytol 2011;57(01):27-30

17 Chaiwong T, Tem-Eiam N, Limpavithayakul M, Boongunha N, Poolphol W, Sukontason KL. Aural myiasis caused by Parasarcophaga (Liosarcophaga) dux (Thomson) in Thailand. Trop Biomed 2014;31(03):496-498

18 Cho JH, Kim HB, Cho CS, Huh S, Ree HI. An aural myiasis case in a 54-year-old male farmer in Korea. Korean J Parasitol 1999;37(01): 51-53

19 Cunningham DG, Zanga JR. Myiasis of the external auditory meatus. J Pediatr 1974;84(06):857-858

20 Davies DM. Human aural myiasis: a case in Ontario, Canada, and a partial review. J Parasitol 1976;62(01):124

21 González Poggioli N, Vázquez Barro JC. [Otic myiasis. Case report]. Acta Otorrinolaringol Esp 2009;60(03):213-214

22 Hatten K, Gulleth Y, Meyer T, Eisenman DJ. Myiasis of the external and middle ear. Ann Otol Rhinol Laryngol 2010;119(07):436-438
23 Iqbal Z, Sharma S, Sami H, Kumar A. Unusual pseudomyiasis with Musca domestica (housefly) larvae in a child with chronic otitis media. Indian J Otolaryngol 2016;22(02):132-134

24 Karaman E, Samasti M, Saritzali G, Ozdemir S, Halil MC, Isildak H. Otomyiasis by Wohlfahrtia magnifica. J Craniofac Surg 2009;20 (06):2123-2124

25 LaCourse SM, Martinez RM, Spach DH, Fang FC. Pain and bloody ear discharge in a returning traveler. Am J Trop Med Hyg 2015;92 (03):599-600

26 Lee HL, Yong YK. Human aural myiasis. Southeast Asian J Trop Med Public Health 1991;22(02):274-275

27 Magliulo G, Gagliardi M, D’Amico R. Human aural myiasis. Otolaryngol Head Neck Surg 2000;122(05):777

28 Maturo S, Michaelson PG, Horlbeck D, Brennan J. Auricular myiasis. Otolaryngol Head Neck Surg 2007;136(04):668-669

29 Mendivil JA, El Shammaa NA. Aural myiasis caused by Cochliomyia hominivorx: case report. Mil Med 1979;144(04):261-262

30 Menghi CI, Gatta CL, Oliva A. [Otomyiasis by Cochliomyia hominivorax in two children from the outskirts of Buenos Aires, Argentina]. Rev Argent Microbiol 2010;42(03):176-178

31 Morris B. First reported case of human aural myiasis caused by the flesh fly Parasarcophaga crassipalpis (Diptera: Sarcophagidae). J Parasitol 1987;73(05):1068-1069

32 Neira P, Muñoz N, Cantero D. [Auricular myiasis cause by Cochliomyia hominivorax (Diptera: Calliphoridae) (Coquerel, 1858)]. Rev Med Chil 2002;130(08):907-909

33 Olatoke F, Afolabi O, Lasisi O, Alabi B, Aluko A. Aural myiasis: Case report from Nigeria. Int J Pediatr Otorhinolaryngology Extra 2011;6(04):233-234

34 Olteanu AI, Enescu A. [Otic myiasis. Clinical and parasitological considerations]. Rev Chir Oncol Radiol O R L Oftalmol Stomatol Otorinolaringol 1979;24(02):139-144

35 Panu F, Cabras G, Contini C, Onnis D. Human auricolar myiasis caused by Wohlfartia magnifica (Schiner) (Diptera: Sarcophagidae): first case found in Sardinia. J Laryngol Otol 2000;114(06): 450-452

36 Rohela M, Jamaiah I, Amir L, Nissapatorn V. A case of auricular myiasis in Malaysia. Southeast Asian J Trop Med Public Health 2006;37(03, Suppl 3):91-94

37 Sharan R, Isser DK. Aural myiasis. J Laryngol Otol 1978;92(08): 705-708

38 Talari S, Yeganeh-moghadam A, Dehghani R. Chrysomya bezziana infestation. Arch Iran Med 2002;5(01):56-58

39 Tligui H, Bouazzaoui A, Agoumi A. [Human auricular myiasis caused by Wohlfahrtia magnifica (Diptera: Sarcophagidae): about three observations in Morocco]. Bull Soc Pathol Exot 2007;100 (01):61-64

40 Uzun L, Cinar F, Beder LB, Aslan T, Altintas K. Radical mastoidectomy cavity myiasis caused by Wohlfahrtia magnifica. J Laryngol Otol 2004;118(01):54-56

41 Werminghaus P, Hoffmann TK, Mehlhorn H, Bas M. Aural myiasis in a patient with Alzheimer's disease. Eur Arch Otorhinolaryngol 2008;265(07):851-853

42 Yaghoobi R, Tirgari S, Sina N. Human auricular myiasis caused by Lucilia sericata: Clinical and parasitological considerations. Acta Med Iran 2005;43(02):155-157

43 Yazgi H, Uyanik MH, Yoruk O, Aslan I. Aural myiasis by Wohlfahrtia magnifica: Case Report. Eurasian J Med 2009;41(03): 194-196

44 Manuel Martín A, Montes I, Domínguez De Luis F. External otitis due to fly larvas. Enferm Infecc Microbiol Clin 2001;19(08): 403-405

45 West JK. Simple and effective field extraction of human botfly, Dermatobia hominis, using a venom extractor. Wilderness Environ Med 2013;24(01):17-22

46 Gallego J, Gallego M. Infecciones causadas por artrópodos. En: Farreras Valenti P, Rozman C. Medicina Interna. 14 ed. Madrid: Harcourt; 2001:2800-2802 
47 Jervis-Bardy J, Fitzpatrick N, Masood A, Crossland G, Patel H. Myiasis of the ear: a review with entomological aspects for the otolaryngologist. Ann Otol Rhinol Laryngol 2015;124(05): 345-350

48 McGraw TA, Turiansky GW. Cutaneous myiasis. J Am Acad Dermatol 2008;58(06):907-926, quiz 927-929
49 Dourmishev AL, Dourmishev LA, Schwartz RA. Ivermectin: pharmacology and application in dermatology. Int J Dermatol 2005;44 (12):981-988

50 Osorio J, Moncada L, Molano A, Valderrama S, Gualtero S, FrancoParedes C. Role of ivermectin in the treatment of severe orbital myiasis due to Cochliomyia hominivorax. Clin Infect Dis 2006;43(06):e57-e59 